\title{
Sobre os Estudos Culturais na América Latina ${ }^{1}$
}

\author{
About Cultural Studies in Latin America \\ En torno a los Estudios Culturales en América Latina
}

\author{
EDUARDO RESTEPRO*
}

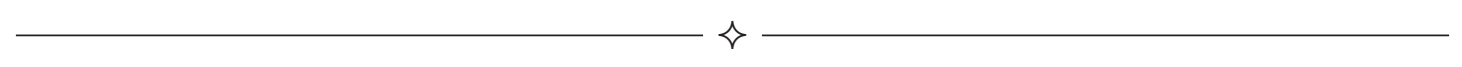

\begin{abstract}
RESUMO - O artigo volta-se para a caracterização dos Estudos Culturais desenvolvidos na América Latina por latino-americanos, questionando a noção estadunidense de que existiria um campo homogêneo de estudos intitulado "Estudos Culturais latino-americanos". Para tanto são apresentados autores e obras de modo a marcar a heterogeneidade, a dispersão, as tendências e influências dos estudos e projetos intelectuais produzidos e atuantes localmente. Argumenta-se que os países da América Latina se caracterizam por uma heterogeneidade radical em termos sociais, políticos, acadêmicos e intelectuais e que, portanto, seria mais adequado referir-se a "Estudos Culturais sobre/desde a América Latina". Por fim, caracterizam-se os chamados "estudos (inter)culturais" a partir da teorização de Catherine Walsh.
\end{abstract}

Palavras-chave - Estudos Culturais. América Latina. Estudos (Inter)Culturais.

\begin{abstract}
This paper addresses the characterization of Cultural Studies developed by Latin Americans, questioning the US notion that there is one homogeneous field called 'Latin American Cultural Studies'. Authors and works are presented to mark heterogeneity, spread, tendencies, and influences of the active locally-produced intellectual studies and projects. It is argued that Latin American countries are characterised by radical heterogeneity in social, political, academic, and intellectual terms. Therefore, it would be more adequate to refer to "Cultural Studies of/from the Latin American perspective". Finally, the so-called "(inter)Cultural Studies" are characterizeds Catherine Walsh refers to it.

Keywords - Cultural Studies. Latin America. (Inter)Cultural Studies.

RESUMEN - El artículo se vuelca para la caracterización de los estudios culturales desarrollados en América Latina por latinoamericanos, que cuestionan la noción estadounidense de que existiria un campo homogéneo de estudios intitulado "Estudios culturales latinoamericanos". Para tal objeto, son presentados autores y obras con el fin de mostrar la heterogeneidad, la dispersión, las tendencias e influencias de los estudios y proyectos intelectuales producidos y actuantes localmente. Se argumenta que los países de América Latina se caracterizan por una heterogeneidad radical en términos sociales, políticos, académicos e intelectuales, y que, por lo tanto, sería más adecuado referirse a "Estudios culturales sobre/desde América Latina". Además que, los llamados "estudios (inter)culturales" se caracterizan a partir de la teorización de Catherine Walsh.
\end{abstract}

Palabras clave - Estudios Culturales. América Latina. Estudios (Inter)Culturales.

Não são poucas as compilações e genealogias (sobretudo as realizadas nos Estados Unidos) que supõem uma equivalência entre os "Estudos Culturais latinoamericanos" e o conjunto de elaborações críticas acerca da cultura desenvolvida por autores latino-americanos. A operação conceitual empreendida consiste em identificar os trabalhos que colocam em relação o cultural e o político (em especial quando se referem ao que se denomina "cultura popular") feitos por latino-americanos desde a América Latina como Estudos Culturais latino-americanos.

Assim, é possível encontrar propostas de definição dos Estudos Culturais latino-americanos que os ancoram, de modo linear, virtualmente em toda a produção crítica latino-americana do século XX:

\footnotetext{
* Doutor em Antropologia pela Universidade da Carolina do Norte em Chapel Hill (Chapel Hill, CN, Estados Unidos da América) e professor na Pontifícia Universidade Javeriana (Bogotá, Colômbia).E-mail: <eduardoa.restrepo@gmail.com>.
} 
Os Estudos Culturais latino-americanos são, em nosso entendimento, um campo de reflexão configurado desde a tradição crítica latino-americana, que se mantém em diálogo constante, muitas vezes conflitivo, com escolas de pensamento ocidental como o estruturalismo francês, o pós-estruturalismo e o pós-modernismo; a linguística, a antropologia e a sociologia da cultura; a Escola de Frankfurt e a teoria da recepção; a semiótica e o feminismo; e, mais recentemente, os Estudos Culturais em suas vertentes anglo-americanas. Paralelamente, a longa e importante tradição de pensamento na América Latina tem muito a ver com o trabalho que iniciou com Bello e Sarmiento e ainda não terminou, sem descartar os pressupostos de tendências crítico-teóricas tão importantes como a teoria da dependência, a pedagogia do oprimido, a teologia da libertação, ou as teorias atinentes à problemática cultural, como a transculturação ou a heterogeneidade, variáveis particulares mais recentes desse pensamento (RÍOS, DEL SARTO Y TRIGO, 2003b, p. 324-325). ${ }^{2}$

Dessa forma, parece que os "Estudos Culturais latino-americanos" constituem um campo muito anterior à existência dessa etiqueta e que reúnem os mais diversos expoentes. A lista de autores incluídos pode ser tão extensa que, em hipótese, abarcaria os ligados à tradição ensaística de finais do século XIX e inícios do XX:

Os textos ensaísticos latino-americanos dos autores já referidos dos séculos XIX e XX mencionaram a necessidade de pensar as diferentes sociedades latinoamericanas a partir das relações étnicas, das emergentes identidades nacionais e da relação entre a modernidade e a modernização. Estes textos fundadores criaram uma prática intelectual que poderíamos chamar de Estudos Culturais avant la lettre (SZURMUKE; McKEE IRWIN, 2009, p. 11).

$\mathrm{Na}$ genealogia proposta por esses autores, considerase não apenas a tradição ensaística latino-americana dos séculos XIX e XX já referida, mas também o diálogo e apropriação de certos enfoques teóricos europeus (a Escola de Frankfurt, o Centro de Estudos Culturais Contemporâneos de Birmingham e o pós-estruturalismo francês) em projetos acadêmicos no sul (os estudos da subalternidade e o pós-colonialismo) e o desenvolvimento de uma agenda de investigação em Estudos Culturais nos Estados Unidos (SZURMUK; McKEE IRWIN, 2009, p. 10). Em outras palavras, desde Szurmuk e Mackee Irwin, os Estudos Culturais latino-americanos são o resultado de uma tradição própria que remonta ao século XIX, mas que não desconhece as apropriações de teorizações europeias, asiáticas e estadunidenses da segunda metade do século XX:
Os Estudos Culturais surgiram como num campo interdisciplinar no mundo anglofalante nos anos cinquenta e sessenta, como parte de um movimento de democratização da cultura. Na América Latina, o uso do conceito de Estudos Culturais é muito mais recente. Ainda que parta da tradição britânica, também tem sua origem em uma tradição que remonta à ensaística do século XIX (SZURMUK; McKEE IRWIN, 2009, p. 9).

Se este é o panorama, não é estranho que produções de autores tão distintos como as do cubano Fernando Ortiz, do princípio do século XX, ou as de José Carlos Mariátegui, Nelly Richard, Nestor García Canclini ou Jesús Martín-Barbero, estejam englobados, também, na rubrica "Estudos Culturais latino-americanos". Alguns autores, inclusive, consideram como parte dos Estudos Culturais algumas intervenções como a gestão cultural e qualquer tipo de articulação com movimentos sociais (sobretudo com os movimentos étnicos).

Uma das preocupações nas formas de apresentação dos Estudos Culturais latino-americanos parece ser a de não considerá-los como simples extensão ou cópia mais ou menos diletante dos estudos britânicos dos anos sessenta ou dos estadunidenses de finais dos anos oitenta e princípios dos noventa. Não reduzi-los a um apêndice tardio dos Estudos Culturais em outras partes do mundo é um gesto que se sustenta no argumento de que os estudos e elaborações críticas que incorporam o cultural na América Latina são Estudos Culturais avant la lettre. Nesse sentido, a introdução de uma coletânea que tem por título The Latin American Cultural Studies reader afirma categoricamente:

Os Estudos Culturais latino-americanos não se originaram nos Estudos Culturais britânicos ou nas teorias ocidentais pós-modernas. Muito antes que os Estudos Culturais britânicos e os escritores pósmodernos chagassem à América Latina, e muito antes do que os Estudos Culturais britânicos fossem constituídos na Grã-Bretanha e o pós-modernismo nascesse muito intelectuais latino-americanos já estavam fazendo algum tipo de Estudos Culturais. Do mesmo jeito, a genealogia dos Estudos Culturais de América Latina é múltipla e eclética, e não se relaciona direta e unicamente com as teorias pós-estruturalistas e pós-modernas. Tampouco são um ramo dos Estudos Culturais dos Estados Unidos, aos que, em realidade, antecedem (TRIGO, 2004, p. 5).

Este delineamento é retomado por vários dos autores identificados com o campo dos Estudos Culturais latinoamericanos quando estes afirmam que eram praticantes deste tipo de estudo, em grupos ou de forma independente, antes que existisse a etiqueta no mundo. Assim, por 
exemplo, numa entrevista muito citada, realizada em 1996, Jesus Martín-Barbero afirmava, em relação a seu trabalho e ao de alguns colegas na América Latina: "Nós fazíamos Estudos Culturais muito antes que esta etiqueta aparecesse". Em sua argumentação, ele assinalava:

Nós fazíamos Estudos Culturais há muito tempo. Na América Latina - no campo da Comunicação, desde a edição do livro de Pascuali nos anos sessenta - havia uma percepção de que os processos de comunicação eram processos culturais. Houve um momento em que Althusser e todas estas coisas apareceram na América Latina e foram percebidas de maneira muito obscura. Foi o meu caso. Não comecei a falar de cultura porque chegaram a mim coisas de fora. Foi lendo Martí, Arguedas que eu a descobri e, com ela, os processos de comunicação a serem analisados. A gente não se ocupava dos meios: estávamos na festa, na casa, na cantina, no estádio. O primeiro que abriu para mim certa contextualização foi Gramsci, e logo descobri, numa viagem de estudos, Thompson, Raymond Williams, Richard Hoggart, os três pais dos Estudos Culturais ingleses. Conheci-os em fins dos anos setenta. [...] Fazíamos Estudos Culturais muito antes que esta etiqueta aparecesse [...] A América Latina não se incorporou aos Estudos Culturais quando a etiqueta virou moda; a história, aqui, é muito distinta (MARTÍN-BARBERO, 1996, p. 4-5).

Martín-Barbero não é uma voz isolada; outros intelectuais vêm argumentando de modo semelhante: "autores como [Garcia] Canclini, Sarlo ou Daniel Mato sustentam que os Estudos Culturais se produziam na América Latina muito antes que se conhecesse o termo" (Anônimo s/f: 20; ver também SZURMUK e MCKEE IRWIN, 2009, p. 16). Assim, certos autores latino-americanos haviam se adiantado ao que constitui a etiqueta dos Estudos Culturais quando esta foi cunhada na Inglaterra, nos anos sessenta; ou, talvez mais adequadamente, o que depois começa a ser identificado, nos anos noventa, como "Estudos Culturais latino-americanos" tem uma densidade histórica e uma genealogia própria. É neste sentido que "muitos críticos questionaram o caráter cosmopolita dos Estudos Culturais, avaliando que na América Latina os Estudos Culturais têm uma tradição própria, anterior à importação dos modelos de práticas de Estudos Culturais originados na academia norte-americana nos anos oitenta e noventa" (SZURMUK; MCKEE IRWIN, 2009, p. 12).

Pois bem, não só os trabalhos de autores latinoamericanos foram incluídos dentro dessa etiqueta. A lista se complementa com outra serie de autores (latinoamericanos ou não) que falam sobre América Latina desde o espaço acadêmico estadunidense. É importante registrar que, nas instituições estadunidenses, uma vez que existem os estudos de áreas (área studies), os latinamerican studies reúnem investigações e trabalhos acadêmicos sobre os países ou regiões da América Latina. Portanto, desde este lugar institucional, os latinamerican Cultural Studies tendem a ser associados ao conjunto de autores e trabalhos que se referem à cultura ou ao cultural - tal como ocorre nos estudos sobre a cultura na América Latina ou sobre a cultura latino-americana. ${ }^{3}$

Seja como uma projeção para o passado dos autores e das tradições na América Latina (Estudos Culturais avant la lettre) ou como um campo dentro dos latinamerican studies, a noção de "Estudos Culturais latino-americanos" merece ser questionada. Antes de tudo, deve-se ter presente que "o rótulo de Estudos Culturais latino-americanos é uma etiqueta de origem estadunidense" (SZURMUK; McKEE IRWIN, 2009, p. 16). Independente da geopolítica da categoria, subsumir uma multiplicidade de autores e projetos intelectuais nesta etiqueta é problemático por várias razões.

Em primeiro lugar, porque se está confundindo estudos sobre a cultura com Estudos Culturais. Já analisei este aspecto em detalhes em outros estudos, e apenas relembro aqui que não é suficiente que se fale de cultura - nem quando se pensa a cultura em suas articulações políticas e em uma posição que vai além das disciplinas - para que a abordagem seja inscrita nos Estudos Culturais. Confundir Estudos Culturais com pensamento crítico cultural, com estudos críticos da cultura ou com teorias contemporâneas culturais é um descuido analítico que opera uma violência epistêmica, geralmente fundada em "simplificações" (para retomar uma expressão de Jesús Martín-Barbero na entrevista citada anteriormente). Portanto, como indica Roberto Follari, "quando se afirma que previamente já se praticavam Estudos Culturais [na América Latina], estamos diante de uma meia-verdade. Estudos sobre a cultura, obviamente, já existiam, e eram feitos pelos mesmos autores que hoje são vinculados aos Estudos Culturais. [...] Falava-se de cultura desde antes, porém se fazia isso de outra maneira" $(2003$, p. 56$){ }^{4}$

Em segundo lugar, porque, como argumenta Daniel Mato (2002), o "nobre" propósito de tornar visível a especificidade e a diferença de uma suposta tradição latino-americana dos Estudos Culturais tem operado um apagamento das heterogeneidades irredutíveis, subsumidas, assim, numa etiqueta que só tem sentido no mercado acadêmico globalizado desde critérios e princípios de inteligibilidade marcadamente estadunidense. Não se ganha muito concebendo o trabalho de Fernando Ortiz, de Aníbal Quijano ou de Orlando Fals Borda como Estudos Culturais e, ao fazê-lo, perde-se bastante na compreensão da heterogeneidade dos significados e efeitos de seus fazeres intelectuais e políticos. 
Em terceiro lugar, porque "o latino-americano" não é, em absoluto, uma marca neutra e sem conflitos. A "obviedade" da adjetivação que remete a uma entidade geo-histórica com supostas comunalidades epistêmicas e sociológicas merece ser questionada em suas possíveis apreciações essencializantes e moralizantes. Retomarei, adiante, a discussão sobre os problemas da ideia genérica de América Latina e do latino-americano, mas já ressalto, aqui, que os "Estudos Culturais latino-americanos" não são da mesma maneira latinoamericanos quando são feitos sobre a América Latina, a partir de um olhar estadunidense e quando o são desde a América Latina (e mais ainda: esse desde merece destacar-se no sentido de que as diferenças de classe, raciais, de gênero, geracionais, institucionais e de lugar contam e são significativas em termos intelectuais e políticos).

Destes questionamentos não se deriva, então, que estejamos considerando que a genealogia dos Estudos Culturais na América Latina seja a que nos coloca numa atitude de réplica mais ou menos adequada dos estadunidenses ou dos britânicos. Consideramos, naturalmente, que existe uma especificidade na América Latina concernente a projetos intelectuais e políticos. Não é apropriado reduzir a heterogeneidade destes, nem concebê-los como simples ramos ou como subcampos de uma totalizadora noção de Estudos Culturais.

Consideramos valiosas as argumentações de John Beverly (2003, p. 336), sobre a existência de distintos projetos intelectuais no contexto latino-americano:

1. os Estudos Culturais, nos quais se enquadram os trabalhos de Nestor García Canclini e Jesús Martín-Barbero;

2. as diferentes vertentes de crítica cultural, que abarcam os estudos de Nelly Richard, Alberto Moreiras e Beatriz Sarlo;

3. os estudos pós-coloniais, nos quais estariam situados os trabalhos de Walter Mignolo;

4. os estudos da subalternidade, nos quais John Beverly situa seu próprio trabalho e o de Ileana Rodríguez, por exemplo.

Independentemente das discussões sobre a conveniência ou não da cartografia sugerida por Beverley, parece-nos acertada a crítica à equiparação simplista entre os "Estudos Culturais latino-americanos" e as tendências (contemporâneas ou não) do "pensamento crítico latinoamericano".

Para ilustrar a dispersão e a heterogeneidade a partir da qual se deveria examinar o lugar dos Estudos Culturais latino-americanos, organizei um diagrama (p. 25), que não pretende ser exaustivo e, sim, dar visibilidade à multiplicidade dos projetos intelectuais constituídos na região, com suas distintas influências.

\section{OS ESTUDOS CULTURAIS A PARTIR DA PERIFERIA}

A crescente circulação da rubrica "Estudos Culturais" em certos países da América Latina deve ser entendida no marco do que alguns afirmam ser sua "internacionalização" (ABBAS; NGUYET, 2004). Ainda que, para alguns pesquisadores, este processo remonte à segunda metade dos anos oitenta, quando os Estudos Culturais são iniciados nos Estados Unidos, somente no início dos anos noventa é que estes se consolidam, atingindo diferentes partes do mundo. Em lugares com tradições intelectuais tão distintas como Austrália, Ásia ou América Latina, a rubrica dos "Estudos Culturais" (com ou sem a adjetivação regional) passa a interpelar as práticas intelectuais de alguns ou é utilizada como marca que engloba uma produção intelectual a partir de seu exterior (é o caso de "Estudos Culturais latinoamericanos", que se aplica também à produção acadêmica estadunidense).

Associado à passagem do Atlântico, indica-se frequentemente que os Estudos Culturais têm passado de um lugar marginal na produção acadêmica - e de uma clara vocação política em suas origens na Inglaterra do pós-guerra - a uma descomunal incorporação no coração da institucionalidade acadêmica nos Estados Unidos, com efeitos de banalização e despolitização. ${ }^{5}$

Isso se reverteu em algumas de suas correntes e concepções, inclusive na Inglaterra. Conforme explica Daniel Mato:

A crescente importância acadêmica dos Cultural Studies nos Estados Unidos e na Grã-Bretanha combina-se à perda da importância de um caráter político que se supunha próprio a estes. Seu caráter político vem se dissolvendo numa retórica da política e dos assuntos de poder que não permite ver as práticas dos atores sociais, que em inglês se denominam social agents. Assim, boa parte dos Cultural Studies, estes que são feitos em inglês, desenvolve-se agentless, ou seja "sem atores sociais"; convertendose em mero assunto de análises de textos e discursos que, no melhor dos casos, são situadas em contextos mas - de todo modo - não comportam práticas sociais especificas (2002, p. 30).

No contexto da América Latina, parece que os Estudos Culturais chegaram para ficar. A incorporação dos Estudos Culturais, em alguns casos, tem se expressado como uma identificação ou como apropriação da rubrica para dar sentido ao trabalho (são criados, inclusive, programas de formação de pós-graduação, eventos ou publicações com a marca dos "Estudos Culturais"). No entanto, em muitos outros casos, esta interpelação se expressa como forte reação ao que se percebe como um modismo acadêmico 


\section{DIAGRAMA \\ Estudos Culturais latino-americanos}

\begin{tabular}{|cllc|}
\hline Primeiras & Transculturação & & \\
décadas & Reyes/Rodó & Fernando Ortiz & Mariátegui \\
século XX & & & C.L.R. James \\
\hline
\end{tabular}

\begin{tabular}{|llll|}
\hline 60-70 & Teologia da libertação & Teoria da dependência \\
Cardoso, Faletto, Prebisch
\end{tabular}

\begin{tabular}{|lllll|}
\hline $\mathbf{7 0}$ & $\begin{array}{l}\text { Estudos críticos } \mathbf{d a} \\
\text { comunicação }\end{array}$ & Antropologia crítica & Sociologia própria \\
Mattelar, Veron & Vasco & Bonfil Batalha & IAP & $\begin{array}{l}\text { Debate sobre } \\
\text { Feudalismo/Capitalismo }\end{array}$ \\
& & Stavenhagen & Fals Borba & \\
& & & Fernandes Laclau, Gunder Frank \\
& & Quijano & \\
\hline
\end{tabular}

\begin{tabular}{|llll|}
\hline $\mathbf{8 0}$ & $\begin{array}{l}\text { Crítica cultural } \\
\text { (desconstrutiva ou neofrankfurtiana) }\end{array}$ & \\
& $\begin{array}{l}\text { Cidade letrada } \\
\text { Rama }\end{array}$ & Antilhanidade & Debate sobre a Modernidade \\
& Geoestética & Estudos Culturais \\
& Glissant & Garcia Canclini, Martin Barbero & Hophnechner \\
& &
\end{tabular}

90 Moraña Moreiras

Pós-ocidentalismo

Coronil Mignolo

\section{Teoria pós-colonial}

Castro-Gomez, Mendieta
Estudos da subalternidade

Rodríguez, Beverley, Rabasa
Ochoa, Miller

Vich Yúdice
Mundialização e pós-imperialismo

Ortiz, Ribeiro

Grosfaguel Mignolo

Estudos (inter)culturais de corte decolonial

Alben, Carvalho, Walsh

\section{Ontologia relacional}

Blaser, de la Cadena, Escobar 
metropolitano (sobretudo estadunidense) que não apenas é alheio às tradições intelectuais próprias, como também abertamente desconhecedora destas. ${ }^{6}$

A partir de Daniel Mato (2002, p. 21), no contexto intelectual e político latino-americano, é pertinente distinguir o que se chama Cultural Studies e o que se nomeia de Estudos Culturais. Os primeiros, que se fazem em inglês, são enquadrados numa tradição anglo-saxônica e definidos predominantemente por suas referências teóricas, autoridades acadêmicas e temáticas. Ainda que possam reivindicar certa especificidade do "latinoamericano" ou do que se faz desde a América Latina, costumam situar Birmingham e seu Centro de Estudos Culturais Contemporâneos como o ponto de origem na genealogia e como paradigma do que se deveria fazer; o que não poucas vezes entra em contradição com o que realmente se faz "porque o projeto dos Cultural Studies, esses que se fazem em inglês, vem se institucionalizando e, ao mesmo tempo, se despolitizando" (MATO, 2002, p. 30). A falta de uma reflexão explicitamente crítica sobre o nome é comum entre os que operam dentro deste modelo que, se seguimos a sugestão de Mato, deve ser chamado Cultural Studies. ${ }^{7}$

Por outro lado, para o referido autor, é possível identificar apropriações estratégicas da rubrica dos Estudos Culturais em trabalhos com conteúdos e agendas próprias, que se evidenciam nas fontes utilizadas, nas temáticas abordadas, nos autores citados, nas autoridades e genealogias traçadas. Esta apropriação estratégica pode ser, por um lado, o resultado de uma reflexão crítica explícita relativamente à "importação descontextualizada" dos Estudos Culturais, mantendo com eles uma relação não definitiva ou, por outro lado, pode ser o resultado de ignorâncias e comodidades de outro tipo (certa burocracia acadêmica que considera tal expressão sedutora para o posicionamento nos mercados de pós-graduação locais ou nacionais).

O posicionamento no imaginário e na produção acadêmica de alguns países da América Latina dos Cultural Studies, incluindo suas importações mais descaradamente descontextualizadas, não impede que se resgate sua articulação com alguns processos interessantes que possibilitam problematizar as mesmas políticas da ignorância sobre as quais se sustentam. ${ }^{8} \mathrm{Em}$ suas argumentações, Daniel Mato não está advogando uma posição nativista assentada em um essencialismo latino-americano que rechaçaria diálogos fecundos, na região, com os Cultural Studies (como, em sua época, o fizeram certas apropriações do marxismo, da semiótica o do feminismo). Seu questionamento é bem mais profundo, e se refere precisamente à geopolítica dos Cultural Studies, quando estes se fazem na/ou sobre a América Latina, tornando invisíveis ou desestruturando projetos intelectuais e políticos de maior envergadura que ele denomina "estudos e outras práticas intelectuais latino-americanas de cultura e poder":

Não proponho adotar uma posição essencialista, isolacionista, nem folclorizante. Não, não se trata disso. Ao contrário, proponho uma posição aberta, de diálogo e intercâmbios transnacionais. Proponho um olhar para o processo de institucionalização dos Cultural Studies que se fazem em inglês não com vocação de autossubordinação, e sim com consciência de contexto, de diferença, de relações de poder, com atitude crítica e olhar transdisciplinar. Assim, poderíamos ver como (as formas pelas quais) a institucionalização desse movimento pode constituir-se para nós numa oportunidade de intercâmbios intelectuais e de construção de alianças para impulsionar e renovar interesses no âmbito das universidades e sociedades latino-americanas, e que, de nossa parte, também possamos oferecer a esse movimento propostas renovadoras. Penso que, antes que traduzir de modo descontextualizado a ideia de Cultural Studies, seria epistemológica, ética e politicamente mais frutífero olharmos nosso contexto mais imediato e encontrar formas de nomear o que, em termos de cultura e poder, está acontecendo - e vem acontecendo há muito tempo - tornar tudo isso mais visível e aprender desde e com outras experiências próximas. Nomear institui, e ao instituir se geram mecanismos de produção, circulação, controle e delimitação dos discursos [...] e das práticas, claro, e se geram também sistemas de legitimação e reconhecimento (MATO, 2002, p. 41).

Esta crítica não é aplicável somente ao que se tem denominado Cultural Studies. Em relação à apropriação estratégica dos Estudos Culturais (seja com ou sem suas marcas regionais ou nacionais), Daniel Mato explica que a importação desta etiqueta como matriz de interpretação do que se produz na região implica a obliteração de relações e práticas intelectuais específicas sobre cultura e poder, com os processos sociais e políticos a partir dos quais têm trabalhado grande parte dos intelectuais na América Latina. Tais relações não podem ser reduzidas a expressões legíveis para a produção acadêmica (publicações, congressos, programas, titulações, etc.).

Independentemente de compartilharmos (como é minha posição) ou rechaçarmos as argumentações de Daniel Mato, não podemos desconhecer que há uma preocupação relativa ao modo de interpretar o crescente interesse nos Estudos Culturais em alguns países de América Latina, bem como sobre a pertinência de apoiar a criação de programas de formação nas universidades em torno deste campo. Nesse sentido, Nelly Richard assinala: 
São muitas as suspeitas e reticências ao mencionar Estudos Culturais na América Latina, onde a tendência é percebê-los como demasiado cativos do horizonte de referências metropolitanas que globaliza o uso e a vigência dos termos postos em circulação por um mercado linguístico de seminários e de congressos internacionais. Para muitos, basta que os Estudos Culturais tenham sido institucionalizados pela fábrica de novidades da academia norte-americana para fazêlos carregar automaticamente o estigma colonizador da dominação metropolitana e para declará-los culpáveis de só favorecer as tecnologias da reprodução que expandem o mercado acadêmico internacional. A moda dos Estudos Culturais estaria apagando a densidade histórica do local e de seus "regionalismos críticos” (RICHARD, 2001, p. 187).

Em seus artigos, tanto Mato como Richard afirmam que os efeitos da subalternização e do borramento da heterogeneidade da região são o resultado de relações de poder globais que permitem entender que os diferentes lugares no "sistema mundo" (WALLERSTEIN, 1996) da academia são constituídos por uma assimetria nas condições de visibilidade (e, ao mesmo tempo, nos silenciamentos) do que se faz, mas também de quem faz e em que termos.

Para aprofundarmos esta ideia, pode ser útil uma perspectiva como a do "sistema mundo", sugerida por Wallerstein (1996). Tal sistema deve ser pensado não apenas nos registros mais óbvios, tais como a ordem econômica ou política mundial, mas também por aspectos mais sutis como as configurações culturais ou, ampliando-o ao que nos interessa, a organização de campos disciplinares ou transdisciplinares. Desde a perspectiva do sistema mundo, estes campos supõem uma densa rede de relações de fluxos e hierarquias, onde a produção acadêmica de certos lugares do mundo se encontra mais bem posicionada que de outros para definir os termos e as condições das discussões no interior de cada campo.

Referindo-se aos Estudos Culturais, Richard (2001) sublinha o poder representacional e codificador que a rede acadêmico-metropolitana exerce sobre o que se reconhece como Estudos Culturais e em que termos o faz. Este poder representacional e codificador opera tanto para os estabelecimentos metropolitanos quanto para os subalternizados situados nas periferias. Como assinala Richard, isso não significa considerar que a rede acadêmico-metropolitana seja homogênea e sem disputas internas, com suas correspondentes heterogeneidades, contra hegemonias e subalternizações. Tampouco significa que os estabelecimentos periféricos só se limitam a copiar de modo diletante o que se define na rede acadêmicometropolitana.
O poder representacional e codificador da rede acadêmico-metropolitana não opera somente através de coerção ou imposição pela força, mas especialmente pela interpelação e produção de subjetividades, pela distribuição de recursos e reconhecimentos (que são, por sua vez, desconhecimentos). Aparatos como as indústrias editorias (o que se publica e como se faz), os programas de formação (com suas bolsas e redes) e as políticas de subvenção são fundamentais para estabelecer os conteúdos e termos dos campos. ${ }^{9}$

É neste marco que poderíamos discutir as geopolíticas do conhecimento para o campo dos Estudos Culturais. Como argumentam Mato (2002) e Richard (2001), estar situado na América Latina e escrever em espanhol (ou inclusive não escrever, para referirmo-nos às outras práticas intelectuais das quais fala Mato) não é o mesmo que se situar no âmbito do pensamento acadêmico estadunidense, assumindo práticas de visibilidade e políticas da ignorância com relação ao que aparece como o campo dos Estudos Culturais (com ou sem sua marca regional). A posição (geocultural, institucional e de enunciação) importa. "Ser falado" ou "poder falar" diz respeito a uma posição que importa, dadas as assimetrias estruturais entre as localidades geoculturais (Estados Unidos, América Latina), as localizações institucionais (estabelecimento metropolitano, estabelecimento periférico) e os lugares de enunciação (falar de/sobre, falar por, falar desde, falar com). ${ }^{10}$ Dito isso, parece relevante não perder de vista a heterogeneidade dessas duas posições, para não pensarmos o assunto em termos de um contraste moralizador e essencialista que tende a desconhecer as diferenças e relações de poder que operam em cada uma, bem como as alianças (perversas em alguns casos; em outros, de aberta solidariedade) entre elas.

O borramento da heterogeneidade, sob a alegação de se estabelecer um princípio de inteligibilidade (efeito das relações de poder que operam no estabelecimento acadêmico metropolitano e em suas relações com os periféricos), é abordada por Nelly Richard quando se refere à distinção entre o latino-americano como diferença diferenciada e como diferença diferenciadora. No primeiro caso, estamos diante de uma homogeneização como o outro (da razão, da ciência, da modernidade, do individualismo, da economia) produto das nostalgias imperiais articuladas pelo estabelecimento acadêmico estadunidense. Daí que o latino-americano seja constituído desde os critérios de legibilidade do estabelecimento metropolitano, de suas aporias e imaginários. É claro, então, que nos encontramos perante uma política da ignorância, do desconhecimento da heterogeneidade irredutível do latino-americano frente às imagens pré-fabricadas de uma outridade monolítica. Como contraposição a esse tipo de política da ignorância, Richard sugere uma política de interrupção do dispositivo 
de codificação e representação metropolitano que se daria mediante uma estratégica "diferença que tenha em si mesma a capacidade de modificar o sistema de codificação das relações identidade-alteridade que busca seguir administrando o poder acadêmico metropolitano" (2001, p. 191).

A noção de Estudos Culturais latino-americanos corre o risco de assumir como uma obviedade a ideia de "latinoamericanidade"; e o problema disso reside em concebêla como uma essência que daria conta de uma diferença constitutiva dos latino-americanos frente a outras gentes (os estadunidenses ou os europeus, por exemplo). Os latino-americanos pensariam ou seriam desta ou aquela forma, em função desta essência compartilhada: a latinoamericanidade. E como essa característica é, assim, pensada como uma diferencia radical em relação ao ocidente e à modernidade, não é estranho que terminemos aceitando imagens que nos apresentam como exóticos a nós mesmos. Em certas ocasiões, estas cristalizações estão carregadas de uma suposta superioridade moral, como tendemos a fazer com as imagens do indígena. A latino-americanidade emerge, então, como garantia de exterioridade e, consequentemente, de autenticidade que costumeiramente é vista como privilégio epistêmico ou político.

Os Estudos Culturais são sempre contextuais e situados, mas disso não se deduz necessariamente que a marcação do Estado-nação (Estudos Culturais colombianos, argentinos ou equatorianos) ou de regiões geo-históricas como América Latina, possa adequadamente localizar e contextualizar a prática dos Estudos Culturais. Em outras palavras, a adjetivação e identificação não correspondem necessariamente a uma contextualização dos estudos produzidos.

A partir do lugar de onde se enunciam os Estudos Culturais formulam-se algumas perguntas, utiliza-se um tipo de bibliografia, ocorrem algumas interlocuções e problemáticas que podem marcar certa especificidade, porém a latino-americanidade é uma entidade heterogênea e muito diversa. Os países da América Latina se caracterizam por uma radical heterogeneidade em termos políticos. O mesmo se pode afirmar das configurações acadêmicas e intelectuais, já que as especificidades das formações nacionais são evidentes. Porém, mais especificamente, as formas de articulação das experiências do latino-americano são múltiplas, dependendo de diferentes fatores. A classe (social) é um dos mais óbvios, bem como os corpos racializados ou etnizados. Entretanto, as exclusões ou subalternizações referidas a esses três fatores (e poderíamos ter mencionado muitos outros) não operam da mesma maneira em distintos momentos nos diferentes países ou regiões da América Latina. Portanto, concordando com Nelly Richard, é mais adequado referir- se a Estudos Culturais sobre/desde a América Latina do que a "Estudos Culturais latino-americanos"; mais ainda, se lembramos que este último termo nos remete aos princípios de inteligibilidade e funcionamento do estabelecimento estadunidense.

\section{ESTUDOS (INTER)CULTURAIS COM INFLEXÃO DECOLONIAL}

O texto "¿Qué saber, qué hacer y cómo ver?..." corresponde à introdução escrita por Catherine Walsh para um livro que reúne os resultados do "Primer Encuentro Internacional sobre Estudios Culturales Latinoamericanos: Retos desde y sobre la Región Andina", realizado em junho de 2001. Como escreve a autora, buscava-se abrir um espaço de diálogo desde a América Latina "sobre a possibilidade de (re)pensar e (re)construir os 'Estudos Culturais' como espaço de encontro político, crítico e de conhecimentos diversos" (2003, p. 12). O encontro, que marca o início do "doctorado en estúdios culturales latinoamericanos de la Universidad Andina", evidencia de imediato o traçado do que posteriormente se denominou inflexão decolonial:

O uso de "Estudos Culturais" não foi - tampouco é casual. Reflete uma urgência cada vez mais evidente nos países andinos de nomear um campo intelectual dirigido ao renovado pensamento crítico inter e transdisciplinar, às relações íntimas entre cultura, política e economia; e o que Mignolo (2000) denomina as epistemologias fronteiriças, incluindo aquelas promovidas pelos movimentos indígenas e afros [...] reflete a necessidade de articular desde a América Latina, porém em relação a outras regiões do mundo, projetos intelectuais, políticos e éticos que põem em diálogo, debate e discussão, pensamentos críticos (no plural), que têm como objetivo compreender e confrontar, entre outras coisas, as problemáticas da colonialidade e interculturalidade, e pensar fora dos limites definidos pelo (neo)liberalismo (WALSH, 2003, p. 13).

Vários são os elementos que, desde então, estão em jogo nesta particular concepção dos Estudos Culturais. Primeiro, o do pensamento crítico inter e transdisciplinar. Às vezes, a partir do conhecido livro de Wallerstein e colaboradores (1996), Abrir las ciências sociales, se afirma a limitação das abordagens disciplinares da cultura, como seria o caso da antropologia cultural ou da sociologia da cultura. Nesse sentido, considera-se que a cultura deve ser pensada em relação com a economia e a política, e não de maneira isolada. Em segundo lugar, aqui já aparece a noção de "epistemologias fronteiriças" e o lugar dos movimentos indígenas e afros. Esta noção será elaborada a partir da argumentação do interepistêmico e 
o descentramento do eurocenstrismo. Terceiro, a ênfase no fato de que se trata de um pensamento crítico desde a América Latina e não simplesmente sobre a região aponta para as geopolíticas do conhecimento e para o lugar de enunciação, marca uma busca não apenas para diferenciar os Estudos Culturais do que se faz nos Estados Unidos sob esta etiqueta, como também para estabelecer uma conexão com as tradições de pensamento crítico latino-americanas. Finalmente, emerge acolonialidade e a interculturalidade como problemáticas que estariam em jogo.

Por isso, Walsh afirma que: "Para nós que estamos inseridos nesta prática, o objetivo não é [...] readotar a prática dos Cultural Studies iniciada na Inglaterra, mas construir pontes de convergência entre projetos intelectuais, entre comunidades interpretativas e entre as disciplinas que estudam o sociocultural, e também entre essas e os saberes locais" (2003, p. 14). É neste sentido, não de simples reprodução dos Cultural Studies ingleses, sem falar de distanciamento com as vertentes menos críticas e textualistas estadunidenses, que Walsh faz referência aos Estudos Culturais alternativos:

Desde meados dos anos noventa e frente à mudança global atual, os Estudos Culturais se encontram em reavaliação e transição, especialmente no hemisfério sul, onde um campo, ou, talvez, melhor dizendo, um projeto de Estudos Culturais alternativos está emergindo, mais vinculado com o pensamento crítico do que com os interesses anteriores das indústrias culturais o do consumo (2003, p. 23).

Esses "Estudos Culturais alternativos" seriam distintos dos Cultural Studies, porém também se diferenciam da primeira geração dos Estudos Culturais latinoamericanos: "É importante fazer uma distinção entre esta primeira geração [Jesús Martín-Barbero e Nestor García Canclini], a primeira escola de Estudos Culturais, e o que estamos chamando Estudos Culturais hoje" (WALSH, 2004, p. 7). É neste sentido que se entende a distinção que Mignolo realiza entre Estudos Culturais e o programa de investigação modernidade/colonialidade:

A versão latino-americana dos Estudos Culturais emergiu no horizonte com os trabalhos de Nestor García Canclini e Jesús Martín-Barbero [...]. García Canclini seguia, mais do que tudo, a linha de Pierre Bourdieu e Jesús Martín-Barbero, que é espanhol, mas residente na Colômbia, tomou elementos de seu interesse na Escola de Frankfurt e de seu trabalho sobre meios. A versão dos Estudos Culturais de García Canclini e Martín-Barbero focaliza os meios, a cidade e as transformações tecnológicas na América Latina. Basicamente, o seu trabalho mais importante pertence à perspectiva da modernidade, seja esta periférica como na América Latina. O programa de investigação de modernidade/colonialidade, e sua consequência necessária, a decolonialidade, situa-se num cenário radicalmente diferente: no lado escuro da modernidade (MIGNOLO, 2007, p. 165).

Em escritos muito mais recentes, Walsh (2010) explicita os traços específicos de sua concepção dos Estudos Culturais, aos quais em diversas ocasiões prefere denominar "estudos (inter)culturais". Ela concebe os Estudos Culturais como um projeto intercultural, interepistêmico e de orientação decolonial. O traço intercultural se entende como um descentramento do eurocenstrismo próprio da modernidade ocidental através do posicionamento de modalidades de existência que têm sido subalternizadas, como é o caso das populações indígenas e afrodescendentes:
O que é intercultural tem sido - e ainda é - eixo central dos processos e lutas de mudança social na região Andina [...]. Assim, nos interessam os espaços de agenciamento, criação, inovação e encontro entre sujeitos, saberes, práticas e visões distintos. É neste sentido que assumimos o intercultural nomeando nosso projeto como estudos (inter)culturais, assim pensando a partir desta região, das lutas, práticas e processos que questionam os legados eurocêntricos, coloniais e imperiais e pretendem transformar e construir condições radicalmente distintas de pensar, conhecer, ser, estar e con-viver (WALSH, 2010, p. 220-221).

O interepistêmico está relacionado com o intercultural. Enfatiza a problematização da geopolítica do conhecimento e da dimensão epistêmica da colonialidade. Supõe a abertura a outros saberes e epistemologias, enquanto horizontes nos quais se pode fundar um projeto decolonial (WALSH, 2010, p. 221). Dada esta concepção, a autora se pergunta se "Estudos Culturais" seria a denominação mais adequada para seu projeto:
A propósito destas diferenças [no interior do que se nomeia como 'Estudos Culturais'] - e particularmente com a emergência, na região, de um progressivo número de programas de Estudos Culturais - questionei se esta nomeação é a mais apropriada para o projeto em que estive envolvida durante os últimos doze anos na Universidad Andina Simón Bolívar no Equador (2010, p. 211).

Sua sugestão de estudos (inter)culturais de cunho decolonial é uma acertada maneira de demarcar os alcances e propósitos do projeto mencionado. Os estudos (inter)culturais de cunho decolonial têm uma posição central no doutorado dirigido por Walsh na Universidade Andina em Quito e têm orientado a concepção dos Estudos 
Culturais de seus diplomados que se encontram em vários países da região. Também no Brasil há uma concepção convergente, sustentada por José Jorge Carvalho (2010). Entretanto, como se deduz claramente do livro editado por Nelly Richard (2010),à exceção de Catherine Walsh, as concepções de Estudos Culturais constituídas pelos autores de distintos países da América Latina não as inscreve no projeto ou vocabulário da inflexão decolonial. Sem desconhecer a relevância dos estudos (inter)culturais de cunho decolonial, os Estudos Culturais, em minha perspectiva, constituem um projeto intelectual e político diferenciado, já que esses últimos caracterizam-se pelo contextualismo radical e pelo antirreducionismo em torno da cultura-como-poder e do poder-como-cultura, no qual o intelectual tem uma vocação política, busca intervir e transformar, porém não se circunscreve a uma política de denúncia do eurocentrismo e da colonialidade.

Esta concepção de Estudos Culturais não desconhece a relevância dos saberes dos setores subalternizados pelos efeitos do eurocentrismo que tem fetichizado o "conhecimento científico" e a academia como os possuidores de uma verdade transcendente, mas não descarta como insumos intelectuais relevantes autores europeus ou estadunidenses como Foucault, Bourdieu, Williams, Wallerstein, Rabinow, Thomson, Gramsci ou Marx, para mencionar apenas alguns. A partir de Chakrabarty (2008), cabe destacar que a atitude intelectual e política frente a esses autores não é a de descartá-los, mas de considerá-los indispensáveis e, ao mesmo tempo, inadequados. Uma tarefa intelectual que, como a dos Estudos Culturais, busca compreender de modo situado e contextual, não pode dar-se ao luxo de descartar em bloco estes aportes devido ao "pecado original" do eurocentrismo, o que não significa que desconheça a relevância de evidenciar as geopolíticas do conhecimento nas quais têm operado e os enclausuramentos que têm conduzido em seu nome.

\section{REFERÊNCIAS}

ABBAS, Ackbar; NGUYET, John Erni. Internationalizing Cultural Studies. London: Blackwell Publishers, 2004.

Anónimo (s/f). Los estudios culturales desde y sobre América Latina.

BERVELEY, John. La persistencia del subalterno. Revista Iberoamericana, v. 69, n. 203, p. 335-342, 2003.

CARVALHO, Jose Jorge. Los estudios culturales en América Latina: interculturalidad, acciones afirmativas y encuentro de saberes. Tabula Rasa, n. 12, p. 229-251, 2010.

CASTRO-GÓMEZ, Santiago. Apogeo y decadencia de la teoría tradicional: una visión desde los intersticios. In: WALSH, Catherine (Ed.). Estudios culturales latinoamericanos. Quito: UASB-Abya-Yala, 2003. p. 59-72.
CHAKRABARTY, Dipesh. Al margen de Europa. ¿Estamos ante el final del predominio cultural europeo? Barcelona: Tusquets, 2008.

MARTÍN-BARBERO, Jesús. Nosotros habíamos hecho estudios culturales mucho antes de que esta etiqueta apareciera. Entrevista a Jesús Martín-Barbero. Dissens, n. 3, p. 47-53, 1996.

FOLLARI, Roberto. Teorías débiles: para una crítica de la deconstrucción y de los estudios culturales. Rosario: Homo Sapiens, 2003.

MATTELART, Armand; NEVEU, Eric. Los Cultural Studies: hacia una domesticación del pensamiento salvaje. La Plata: Universidad Nacional de La Plata, 2002.

MATO, Daniel. Estudios y otras prácticas latinoamericanas en cultura y poder. In: MATO, Daniel (Ed.). Estudios y otras prácticas latinoamericanas en cultura y poder. Caracas: Clacso, 2002. p. 21-43.

MIGNOLO, Walter. Introduction. Coloniality of power and decolonial thinking. Cultural Studies, v. 21, n. 2-3, p. 155-167, 2007.

REYNOSO, Carlos. Apogeo y decadencia de los estudios culturales: una mirada antropológica. Barcelona: Gedisa, 2000.

RICHARD, Nelly. Globalización académica, estudios culturales y crítica latinoamericana. In: MATO, Daniel (Ed.). Estudios latinoamericanos sobre cultura y transformaciones sociales en tiempos de globalización. Buenos Aires: Clacso, 2001. p. 185-199.

RÍOS, Alicia; SARTO, Ana del; TRIGO, Abril. Presentación. Los estudios culturales latinoamericanos hacia el siglo XXI. Revista Iberoamericana, v. 49, n. 203, p. 323-331, 2003.

SZURMUK, Mónica; MCKEE IRWIN, Robert (Eds.). Presentación. Diccionario de estudios culturales latinoamericanos. México: Siglo XXI, 2009. p. 9-42.

TRIGO, Abril. General introduction. In: RÍOS, Alicia; SARTO, Ana del; TRIGO, Abril (Ed.). The Latin American Cultural Studies reader. Durham: Duke University Press, 2004. p. 1-14.

VALENZUELA, José Manuel. Los estudios culturales en México. México: Fondo de Cultura Económica, 2003.

VEGA, Renán. Los estudios culturales: un ejemplo de dependencia académica e intelectual. In: VEGA, Renán. Un mundo incierto, un mundo para aprender y enseñar: las transformaciones mundiales y su incidencia en la enseñanza de las ciencias sociales. Bogotá: Universidad Pedagógica Nacional, 2007. p. 80-90.

WALSH, Catherine. ¿Qué saber, qué hacer y cómo ver? Los desafíos y predicamentos disciplinares, políticos y éticos de los estudios (inter)culturales desde América andina. In: WALSH, Catherine (Comp.). Estudios culturales latinoamericanos: retos desde y sobre la región Andina. Quito: Universidad Simón Bolívar/Abya-Yala, 2003. p. 11-28.

WALSH, Catherine. Introducción. (Re)pensamiento crítico y (de)colonialidad. In: WALSH, Catherine (Ed.). Pensamiento crítico y matriz (de)colonial: reflexiones latinoamericanas. Quito: UASB-AbyaYala, 2004. p. 13-35.

WALSH, Catherine. Acerca de los estudios culturales. Entrevista. Revista Sigma, p. 7-13, 2004.

WALSH, Catherine. Estudios (inter)culturales en clave decolonial. Tabula Rasa, n. 12, p. 209-277, 2010. 
WALLERSTEIN, Immanuel. La reestructuración capitalista y el sistema mundo. Anuario Mariateguiano, Lima, v. 8, n. 8, p. 1-14, 1996.

WALLERSTEIN, Immanuel et al. Open the social sciences. Report of the Gulbenkian Commission on the Restructuring of the Social Sciences. Stanford: Stanford University Press, 1996.

\section{Notas}

1 Tradução para o português de Anuncio Marti Mendez.

2 Esta mesma definição aparece na introdução da The Latin American Cultural Studies Reader, assinada por Abril Trigo (2004, p. 3-4).

3 Por isso, no Diccionario de estúdios culturales latinoamericanos, Szurmuk e McKee Irwin argumentam que: "O termo Estudos Culturais é usado para referir-se a um leque de metodologias interdisciplinares de investigação. Neste dicionário nos ocupamos especificamente da área dos Estudos Culturais latino-americanos, um investimento interdisciplinar e multifacetado, focado na cultura latino-americana" (2009: 7).

4 Um dos exemplos extremos de equivalência entre Estudos Culturais e teoria cultural (incluso não necessariamente crítica) encontra-se no livro compilado por Valenzuela (2003) para México.

5 Para uma discussão mais alongada sobre a banalização e despolitização referidas neste texto, pode-se consultar o vídeo de Roberto Follari no seguinte link: <bdigital.uncu.edu.ar/fichas.php?idobjeto=440 $>$. Não obstante, sobre as generalizações rápidas que descartam em bloco as práticas e possibilidades dos Estudos Culturais nos Estados Unidos, Nelly Richard afirma: "Existem linhas de ambiguidade e de contradição no interior do programa acadêmico dos Estudos Culturais que, inclusive nos Estados Unidos, abrem linhas de fuga dentro de seu formato aparentemente tão seriado. Contra os próprios limites de burocratização acadêmico-universitária dos Estudos Culturais, é sempre possível prestar atenção às formas alternativas mediante as quais - para retomar uma fórmula de Jameson - 'o desejo' chamado 'Estudos Culturais' luta contra sua própria ortodoxia institucional [...]. A liberdade que ganharmos para deslocarmo-nos por entre as codificações institucionais do saber acadêmico, nos permitirá recombinar estrategicamente determinadas articulações de debate segundo as prioridades de cada um de nossos contextos e os jogos de força que os atravessam" (2001: 189).

6 Entre os autores que rechaçam os Estudos Culturais com este argumento de irrelevante moda intelectual metropolitana se encontram Carlos Reynoso (2000), Roberto Follari (2003) y Renán Vega (2007). O livro de Reynoso, que basicamente argumenta que os Estudos Culturais são combinação de teoria pós-moderna, banalidade temática y ligeireza metodológica, tem se convertido num clássico desta posição e, ao menos entre os antropólogos mais conservadores disciplinarmente, é a única referência dos Estudos Culturais. Para uma referência mais ampla ao livro de Reynoso, pode-se consultar o artigo de Santiago Castro-Gómez (2003).

7 Nisto coincidem as discussões de Mato com as de Matellart e Neuveu (2002).

8 Embora os alcances e alguns dos mecanismos destas importações são bem particulares do campo transnacional dos Cultural Studies e das transformações do sistema mundial nas últimas três décadas, tampouco se pode desconhecer que este tipo de "gestos de autossubmissão irreflexiva" encontra um fundamento nada desprezível em práticas de larga data na região.

9 Com seu alcance praticamente mundial, contribuem para a definição do sentido comum de cada campo: as autoridades, autorizações e sensibilidades relevantes, as hierarquizações de objetos, marcos conceptuais e estratégias metodológicas; a sedimentação de práticas escriturais e argumentativas, e o estabelecimento dos termos da profissionalização de seus praticantes.

${ }_{10}$ Retomo aqui, com algumas modificações específicas, os níveis analíticos sugeridos por Richard (2001, p. 188-189).

Artigo recebido em setembro 2014.

Aprovado em fevereiro 2015. 